\title{
Effects of Yaji on Some Biochemical and Haematological Indices in Albino Wistar Rats
}

\author{
Chilaka Ugochinyere Jane ${ }^{1, \text { *, Chilaka Kingsley Chimsorom², Meludu Samuel }}{ }^{3}$, \\ Chukwu Leoclincton ${ }^{4}$ \\ ${ }^{1}$ Department of Haematology, Nnamdi Azikiwe University Teaching Hospital, Nnewi, Nigeria \\ ${ }^{2}$ Department of Pharmacology, Nnamdi Azikiwe University, NnewiCampus, Nnewi, Nigeria \\ ${ }^{3}$ Department of Biochemistry, Nnamdi Azikiwe University, Okofia Campus, Nnewi, Nigeria \\ ${ }^{4}$ Department of Pharmacology and Therapeutics, Chukwuemeka Odumegwu Ojukwu University, Awka Campus, Awka, Nigeria
}

Email address:

lindajenny2002@yahoo.com (C. U. Jane), chilakakingsley@yahoo.com (C. K. Chimsorom), sc.meludu@unizik.edu.ng (M. Samuel), lenergy_chuks@yahoo.com (C. Leoclincton)

${ }^{*}$ Corresponding author

\section{To cite this article:}

Chilaka Ugochinyere Jane, Chilaka Kingsley Chimsorom, Meludu Samuel, Chukwu Leoclincton. Effects of Yaji on Some Biochemical and Haematological Indices in Albino Wistar Rats. Clinical Medicine Research. Vol. 8, No. 3, 2019, pp. 63-68. doi: 10.11648/j.cmr.20190803.12

Received: June 3, 2019; Accepted: August 9, 2019; Published: August 26, 2019

\begin{abstract}
Yaji is a mixture of spices and additives that is used as sauce for meat delicacy in Nigeria called suya. Its effects on the body weight, index of liver function, on lipid profile, kidney function and some haematological indices were the main focus of this study. A total of 50 Wistar rats with average weight of 200 grams were randomly divided into five experimental groups: A, B, C, D and E. Each group consisted of ten animals. Baseline blood sample was collected from each animal. Group A was the control group while groups B to E were the treatment groups. Group A was given $100 \%$ chicken mesh, group B with $75 \%$ of chicken mesh $+25 \%$ of yaji, group C with $50 \%$ of chicken mesh $+50 \%$ of yaji, group D with $25 \%$ of chicken mesh + $75 \%$ of yaji, group E with $100 \%$ of yaji. The experiment lasted for 30days. There was a significant increase in some atherosclerotic index: Total Cholesterol (TC) and Triglyceride (TG), while the level of Low Density Lipoprotein (LDL) only increased at very high percentage of yaji intake but High Density Lipoprotein (HDL) increased at moderate intake of yaji. Sodium and Chloride ions were significantly increased while Potassium and Bicarbonate ions decreased significantly compared to the controls with urea and creatinine levels remaining unchanged. There was also a significant decrease in Packed Cell Volume (PCV) as the proportion of yaji increased in relation to their feed while White Blood Cell Counts, total and differential were unchanged. The changes in weight did not show any statistical difference from the control. The consumption of the meat sauce, Yaji and its spices may have adverse health implications if consumed in higher quantity than the normal diet and therefore should be consumed only occasionally.
\end{abstract}

Keywords: Yaji, Aspartate and Alanine Amino Transferases, Alkaline Phosphatase, Total Cholesterol,

High Density Lipoprotein, Low Density Lipoprotein, Serum Electrolytes, Urea and Creatinine

\section{Introduction}

\subsection{Background}

There is a growing concern about the indiscriminate and massive consumption rate of Yaji, which, in recent years, has been the basis of several scientific investigations [1]. Some of the findings from such investigations show that an excessive consumption of Yaji has the capability to induce pancreatic, liver, kidney and brain damages [2]. These findings further illuminate the fears that an unregulated production and consumption of Yaji, portends serious dangers to the health of its consumers. Of importance also, are the reports that some of the active ingredients in Yaji, like capsaicin, piperine and monosodium glutamate possess excitotoxic and apoptotic potentials [3, 4].

This Nigerian meat sauce known as Yaji is a complex 
physical mixture of groundnut cake powder, additives, spices and salt [5]. Its main constituent is the groundnut cake, while the constituent spice-ginger, garlic, clove, red pepper and black pepper [6] contains gingerol [7], allicin, eugenol [8], capsaicin [9] and piperine [10] as active principles respectively.

Gingerol, which is an active component in ginger has been used to induce a hypothermic state in rats [11] and seems to be effective in an animal model of rheumatoid arthritis [12]. Gingerol has also been investigated for its effect on cancerous tumours in the bowel [13], breast tissue [14], ovaries [15], the pancreas, among other tissues with positive results.

Eugenol, the main component found in cloves has been found to kill certain human colon cancer cell lines in vitro but has also been documented to be hepatotoxic [16]. Overdose is possible, causing a wide range of symptoms from blood in the patient's urine, to convulsions, diarrhoea, nausea, unconsciousness, dizziness, or rapid heartbeat [17].

Capsaicin is used to treat minor aches and pains of the muscles and joints (e.g. arthritis, backache, sprains). It may also be used to treat nerve pain but causes severe dizziness and respiratory distress as side effect [18].

Capsaicin is actually an irritant to humans, producing a burning sensation in any tissue it touches. It works by depleting or interfering with autocoids such substance $\mathrm{P}$, a chemical involved in transmitting pain impulses to the brain. The properties of capsaicin make it an option for relieving pain associated with osteoarthritis, rheumatoid arthritis, and diabetic neuropathy [19].

Piperine, the active component of black pepper is involved to increase the absorption of other nutrients in the body and has other novel applications as well - such as helping to fight gastrointestinal cancer and having a central nervous system effect while enhancing the cognitive functions of the brain [20].

Black pepper contains several potent antioxidants and is thus one of the most important species for preventing and curtailing oxidative stress. This complex mixture of spices and additives has active ingredients which on individual basis, are known to have side effects if consumed in excess. The growing concern is that the excessive consumption of Yaji signifies an excessive consumption of a combination of these constituents which are mixed without a standardized format [6].

\subsection{Rationale for Study}

The in vivo effects of consumption of Yaji to the health of its consumers have been of interest in several quarters. Thus, it is needful to ascertain the safe use or otherwise of Yaji meat sauce since its production and consumption are yet to be regulated.

\subsection{Statement of Problem}

By virtue of the powerful phytochemicals they contain, these additives and spices are known to exhibit an array of biochemical and pharmacological activities including antioxidant and anti-inflammatory properties that are believed to contribute to their anticarcinogenic and antimutagenic activities [21].

\section{Materials and Methods}

\subsection{The Substance of Study}

The local meat sauce Yaji and its constituent spices: clove, ginger, garlic black pepper, red pepper and monosodium glutamate (ajinomoto) were purchased from Nkwo market, Nnewi, Anambra State and identified by a taxonomist, $\mathrm{Mr}$ NwaruChijioke Maxwell of the Botany Department, NnamdiAzikiwe University Awka Campus. Also, animal feeds in the form of chicken mesh were bought from the same market. The spices and animal feeds were crushed separately using an electric blender. Measurement of spices was carried out using electric balance.

\subsection{Proportions of Components of Yaji}

Ground nut cake powder (Yaji) 50\%, Ajinomoto/Monosodium Glutamate 10\%, Ginger10\%, Cloves 10\%, Garlic cloves 10\%, Black pepper5\%, Red pepper5\%. Yaji as a meat sauce is a local preparation; therefore the quantity of constituents may differ in some localities. However, the proportion used in this study was got from an interview with some individuals from the Northern states of Nigeria who are the main producers of suya and its sauce, yaji that have their business centres (suya spots) located at Eke Amobi, Izuchukwu park and Abada junction, all in OtoloNnewi.

Fifty-five adult male rats weighing $180 \mathrm{~g}$ to $220 \mathrm{~g}$ were obtained and maintained in the laboratory. They were acclimatized to the laboratory conditions two weeks before the start of experiment and caged in a room temperature. The rats were fed according to their group diet and water ad libitum. Five of these acclimatized animals were sacrificed for baseline parameters viz: serum lipid profile, liver function test urea and creatinine assessment.

The study was conducted in the animal house of NnamdiAzikiwe University Okofia Campus, Nnewi.

\subsection{Study Design}

The rats were randomly divided into five (5) experimental groups: A, B, C, D and E. Every group consisted of ten (10) animals. Group A was the control group while groups B to E were the treatment groups. Group A was given $100 \%$ chicken mesh, group B was fed with $75 \%$ of chicken mesh + $25 \%$ of Yaji, group C was fed with $50 \%$ of chicken mesh + $50 \%$ of Yaji, group D was fed with $25 \%$ of chicken mesh + $75 \%$ of Yaji, group E was fed with $100 \%$ of Yaji. All the feed were prepared into pellets prior to administration. Food and water were supplied ad libitum. The experiment lasted for 30days. 
Baseline samples were collected at the beginning of the experiment and at the end of the experiment, the rats were sacrificed and blood was collected. The blood was collected in both plain bottles and Ethylene Diamine Tetra acetic Acid (EDTA) bottles for biochemical and haematological analysis respectively.

The source of water was pipe-borne water (tap water).

\subsection{Analytical Methods}

The plasma concentration of Triglyceride, Total cholesterol and High Density Lipoprotein-Cholesterol (HDL-C) were measured using standard spectrophotometric methods.

Serum total cholesterol is determined by enzymatic method as described by Allainet al., (1974).

Serum triglyceride is determined using an enzymatic colorimetric method as described by Bucolo and David; (1973).

Serum HDL-cholesterol is determined using precipitation method as described by Benzie, (1979).

Serum LDL-cholesterol is determined using Friedwald's formular as described by Friedewald et al., (1972) method.

Serum alanineaminotransferaseis determined using spectrophotometric method as described by Reitman and Frankel, 1957.

Serum aspartateaminotransferaseis determined using spectrophotometric method as described by Rietman and Frankel, (1957).

Serum alkaline phosphate is determined using spectrophotometric method (Bessey et al., 1972).

The white cell count (WBC) is determined by the total number of leukocytes in a volume of blood as described by Dacie and Lewis (2001).

Packed Cell Volume was determined by centrifuging anticoagulated blood in a glass capillary as described by Cheesbrough (2002).

Electrolytes estimation as described by Martin Frank, 1994.

Blood urea concentrations estimation by Berthelot's reaction as described by Kaplan and Teng (1982).

Creatinine Estimation using the Reflotron Dry Chemistry Analyzer as described by Estridgeet al, 2000.

\subsection{Data Analysis}

Results of the experiment were subjected to a one way Analysis of Variance (ANOVA) using statistical package for social sciences (SPSS) version 16 and presented as Mean \pm Standard Deviation. The means of all the test groups and the control (group A) were compared for four weeks. Values of $\mathrm{p}$ $<0.05$ were considered statistically significant.

\section{Results}

Table 1. Lipid profile before and after intake of different proportions of yaji in albino wistar rats.

\begin{tabular}{|c|c|c|c|c|c|c|}
\hline & & \multicolumn{5}{|c|}{ Mean \pm SD N $=5$} \\
\hline & & Group A & Group B & Group C & Group D & Group E \\
\hline & & $100 \%$ feed & $25 \%$ yaji & $50 \%$ yaji & $75 \%$ yaji & $100 \%$ yaji \\
\hline \multirow{3}{*}{ T. C } & After & $2.25 \pm 0.02$ & $2.26 \pm 0.03$ & $2.6 \pm 0.04$ & $3.26 \pm 0.22$ & $5.21 \pm 0.14$ \\
\hline & Paired t-test & 2.16 & -0.38 & -21.83 & -9.74 & -41.76 \\
\hline & p-value & 0.097 & 0.721 & $0.000 *$ & $0.001^{*}$ & $0.000 *$ \\
\hline \multirow{3}{*}{ HDL-C } & After & $1.33 \pm 0.05$ & $1.20 \pm 0.06$ & $1.28 \pm 0.03$ & $1.40 \pm 0.03$ & $1.51 \pm 0.06$ \\
\hline & Paired t-test & -3.21 & 1.66 & -1.38 & -12.52 & -13.46 \\
\hline & $\mathrm{p}$-value & $0.032 *$ & 0.172 & 0.24 & $0.000^{*}$ & $0.000^{*}$ \\
\hline \multirow{3}{*}{ LDL-C } & Baseline & $0.77 \pm 0.03$ & $0.76 \pm 0.02$ & $0.77 \pm 0.02$ & $0.77 \pm 0.03$ & $0.77 \pm 0.03$ \\
\hline & After & $0.95 \pm 0.14$ & $0.75 \pm 0.07$ & $0.65 \pm 0.04$ & $0.62 \pm 0.06$ & $1.56 \pm 0.10$ \\
\hline & Paired t-test & -2.45 & 0.25 & 12.51 & 3.8 & 17.07 \\
\hline \multirow{4}{*}{ TG } & Baseline & $0.48 \pm 0.02$ & $0.48 \pm 0.02$ & $0.47 \pm 0.02$ & $0.48 \pm 0.02$ & $0.46 \pm 0.04$ \\
\hline & After & $0.44 \pm 0.03$ & $0.31 \pm 0.08$ & $0.25 \pm 0.05$ & $1.13 \pm 0.22$ & $2.23 \pm 0.32$ \\
\hline & Paired t-test & 2.59 & 4.95 & 7.83 & -6.33 & -11.84 \\
\hline & p-value & 0.061 & $0.008 *$ & $0.001^{*}$ & $0.003 *$ & $0.000 *$ \\
\hline
\end{tabular}

* Shows that the level is significant $(\mathrm{p}<0.05)$

TC: Total Cholesterol (mmol/l) - Groups C, D, E significantly elevated

HDL-C: High Density Lipoprotein (mmol/l) - Groups A, D, E significantlyelevated

Elevated: Low Density Lipoprotein (mmol/l) - Groups C, D, E significantly reduced

TG: Triglyceride (mmol/l) - Groups C, D significantly reduced, E elevated 
Table 2. The results of liver enzymes before and after intake of different proportions of yaji in albino wistar rats.

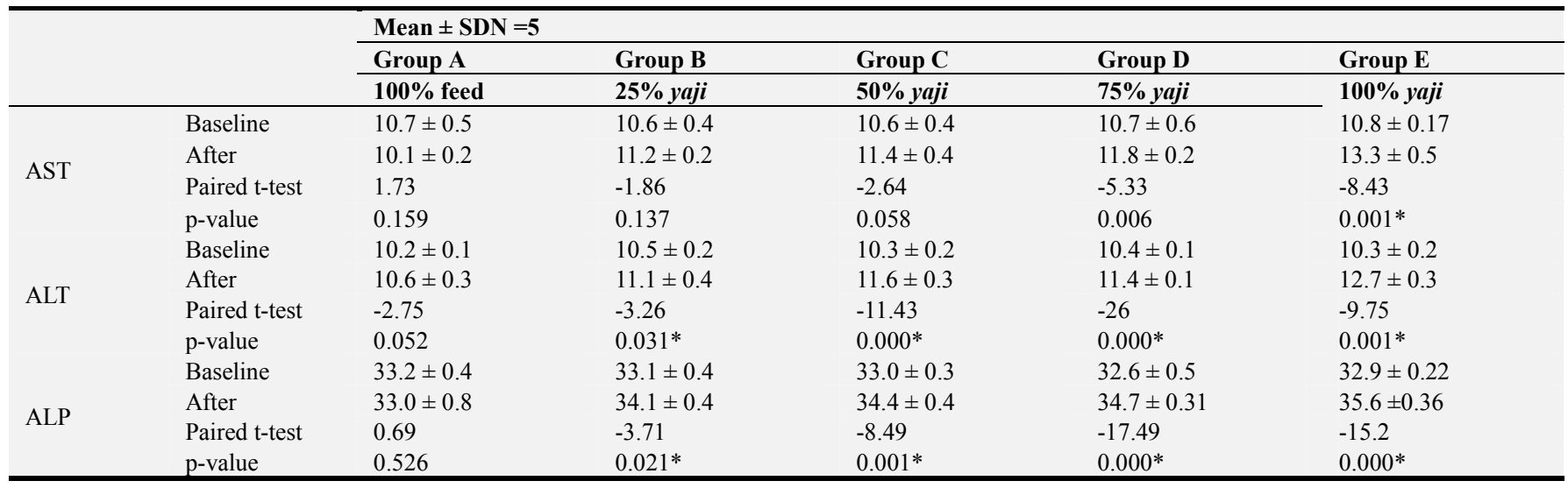

* Shows that the level is significant $(\mathrm{p}<0.05)$

AST - Aspartate amino Transferase (iu/l) - Group E significantly elevated

ALT - Alanine amino Transferase (iu/l) - Groups B, C, D, E significantly elevated

ALP - Alkaline Phosphatase (iu/l) - Groups B, C, D, E significantly elevated

Table 3. The results of renal profile before and after intake of different proportions of yaji in albino wistar rats.

\begin{tabular}{|c|c|c|c|c|c|c|}
\hline & & \multicolumn{5}{|c|}{ Mean \pm SDN $=5$} \\
\hline & & Group A & Group B & Group C & Group D & Group E \\
\hline & & $100 \%$ feed & $25 \%$ yaji & $50 \%$ yaji & $75 \%$ yaji & $100 \%$ yaji \\
\hline \multirow{4}{*}{ UREA } & Before & $5.76 \pm 0.7$ & $5.48 \pm 0.8$ & $5.48 \pm 0.8$ & $5.94 \pm 0.5$ & $6.32 \pm 0.8$ \\
\hline & After & $5.70 \pm 0.7$ & $5.44 \pm 0.7$ & $5.48 \pm 0.6$ & $5.90 \pm 0.5$ & $6.28 \pm 0.6$ \\
\hline & Paired t-test & 0.51 & 0.23 & 0 & 0.3 & 0.14 \\
\hline & p-value & 0.634 & 0.828 & 1 & 0.778 & 0.896 \\
\hline \multirow{4}{*}{$\mathrm{Cr}$} & Before & $113.2 \pm 0.9$ & $113.6 \pm 0.7$ & $113.8 \pm 0.8$ & $112.8 \pm 2.0$ & $113.3 \pm 0.5$ \\
\hline & After & $113.6 \pm 0.5$ & $113.1 \pm 0.6$ & $113.6 \pm 0.8$ & $112.9 \pm 2.0$ & $113.4 \pm 0.5$ \\
\hline & Paired t-test & -1 & 0.9 & 0.89 & -0.89 & -0.33 \\
\hline & p-value & 0.373 & 0.419 & 0.426 & 0.426 & 0.757 \\
\hline
\end{tabular}

Urea $\mathrm{mmol} / \mathrm{l}$

Creatinine $\mathrm{mg} / \mathrm{dl}$

Table 4. The results of electrolytes with different proportions of yaji in comparism with control in albino wistar rats.

\begin{tabular}{lllll}
\hline \multirow{2}{*}{ Parameters/Groups } & Mean \pm SDN $=\mathbf{5}$ & & Potassium mmol/I & Bicarbonate mmol/I \\
\cline { 2 - 5 } & Sodium mmol/I & Chloride mmol/I & $4.44 \pm 0.167$ & $23.80 \pm 1.304$ \\
\hline $100 \%$ feed (control)A & $142.80 \pm 2.168$ & $96.00 \pm 1.000$ & $4.160 \pm 0.114$ & $23.60 \pm 1.140$ \\
$25 \%$ yaji\&75\%feedB & $146.40 \pm 1.34$ & $97.6 \pm 2.30$ & $3.900 \pm 0.255 \mathrm{a}$ & $22.20 \pm 1.095$ \\
$50 \%$ yaji\&50\% feedC & $148.60 \pm 1.67 \mathrm{a}$ & $103.6 \pm 1.52 \mathrm{a}$ & $3.600 \pm 0.200 \mathrm{a}$ & $21.40 \pm 0.510 \mathrm{a}$ \\
$75 \%$ yaji\&25\% feedD & $163.80 \pm 2.78 \mathrm{a}$ & $114.2 \pm 3.11 \mathrm{a}$ & $3.180 \pm 0.110 \mathrm{a}$ & $21.00 \pm 1.225 \mathrm{a}$ \\
$100 \%$ yajiE & $177.60 \pm 2.88 \mathrm{a}$ & $116.6 \pm 1.82 \mathrm{a}$ & 37.892 & 5.714 \\
F - value & 209.59 & 102.76 & 0 & 0.003 \\
P - value & 0 & 0 & & \\
\hline
\end{tabular}

$\mathrm{a}=$ significance when compared with control

Table 5. The results of packed cell volume and white blood cell count with different proportions of yaji in comparism with control in albino wistar rats.

\begin{tabular}{|c|c|c|c|c|}
\hline \multirow{2}{*}{ Parameters/Groups } & \multicolumn{4}{|l|}{ Mean \pm SDN $=5$} \\
\hline & PCV \% & NEUT (\%) & LYMPH (\%) & MONO (\%) \\
\hline $100 \%$ feed (control)A & $41.60 \pm 3.58$ & $41.40 \pm 2.191$ & $49.40 \pm 1.140$ & $8.40 \pm 1.817$ \\
\hline $25 \%$ yaji $\& 75 \%$ feedB & $39.60 \pm 1.673$ & $41.40 \pm 2.074$ & $48.80 \pm 1.789$ & $9.40 \pm 3.782$ \\
\hline $50 \%$ yaji $\& 50 \%$ feedC & $38.40 \pm 1.673$ & $42.20 \pm 1.789$ & $48.60 \pm 1.140$ & $9.20 \pm 1.643$ \\
\hline $75 \%$ yaji $\& 25 \%$ feedD & $33.60 \pm 1.673 a$ & $42.60 \pm 1.949$ & $47.80 \pm 1.095$ & $8.80 \pm 1.304$ \\
\hline $100 \%$ yajiE & $26.40 \pm 1.673 a$ & $42.16 \pm 1.993$ & $45.60 \pm 2.510$ & $10.00 \pm 1.581$ \\
\hline $\mathrm{F}$ - value & 38.533 & 0.731 & 4.113 & 0.376 \\
\hline$P$-value & 0 & 0.582 & 0.014 & 0.823 \\
\hline
\end{tabular}

$\mathrm{a}=$ significance when compared with control 
Table 6. The weight of rats with different proportions of yaji in comparism with control assessed before and after four weeks consumption of yaji.

\begin{tabular}{lllll}
\hline & $\mathbf{1}^{\text {st }}$ week & $\mathbf{4}^{\text {th }}$ week & Paired t-test & P-value \\
\hline $100 \%$ feed & $198.00 \pm 17.90$ & $226.00 \pm 26.08$ & 1.633 & 0.178 \\
$25 \%$ yaji & $194.00 \pm 8.94$ & $216.00 \pm 20.74$ & 3.207 & $0.033^{*}$ \\
$50 \%$ yaji & $183.00 \pm 4.47$ & $194.00 \pm 19.49$ & 2.582 & 0.061 \\
$75 \%$ yaji & $203.00 \pm 10.95$ & $196.00 \pm 20.74$ & 2.449 & 0.07 \\
$100 \%$ yaji & $197.00 \pm 4.47$ & $196.00 \pm 8.94$ & 1 & 0.374 \\
\hline
\end{tabular}

* Shows that the level is significant $(\mathrm{p}<0.05)$

Table 7. The weight of rats with different proportions of yaji in comparism with control in albino wistar rats.

\begin{tabular}{llll}
\hline \multirow{2}{*}{ Parameters/Groups } & Mean \pm SDN $=5$ & & \\
\cline { 2 - 4 } & WT IN Kg WEEK 1/ BASELINE & WT IN Kg WEEK 2 & WT IN Kg WEEK 3 \\
\hline 100\% feed (control)A & $198.00 \pm 17.90$ & $196.00 \pm 35.78$ & $214.00 \pm 2.93$ \\
$25 \%$ yaji\&75\%feedB & $194.00 \pm 8.94$ & $184.00 \pm 16.73$ & $194.00 \pm 15.17$ \\
$50 \%$ yaji\&50\% feedC & $183.00 \pm 4.47$ & $166.00 \pm 8.944$ & $184.00 \pm 15.17$ \\
$75 \%$ yaji\&25\% feedD & $203.00 \pm 10.95$ & $206.00 \pm 21.91$ & $200.00 \pm 14.14$ \\
$100 \%$ yajiE & $197.00 \pm 4.47$ & $194.00 \pm 8.94$ & $202.00 \pm 10.95$ \\
F - value & 2.478 & 2.605 & 1.942 \\
P - value & 0.077 & 0.067 & 0.143 \\
\hline
\end{tabular}

\section{Discussion}

Results of the serum lipid profile, Total Cholesterol (TC), Triglycerides (TG), Low Density Lipoprotein (LDL) as well as in High Density Lipoproteins (HDL) in rats; show that there was a progressive increase in the Total Cholesterol as the dosage of Yaji increased from $25 \%$ to $100 \%$. This could be attributed to the high proportion of groundnut (Arachis hypogeal L) cake which forms $50 \%$ of the entire Yaji preparation. Groundnut cake is rich in fats and oil [22, 23] which is a rich source of lipids. These high levels of fats and oil in the groundnut cake may overwhelm the rats' enzymes responsible for lipid metabolism, hence the significant increase in all the serum lipids estimated compared to baseline values. Another possible explanation for the rise in serum lipid profile is that Yaji, a complex mixture of constituents also contains Monosodium Glutamate (MSG). It has been reported that MSG alters the regulatory mechanism that affects fat metabolism [24]. This study also shows that Yaji as a complex mixture has the potentials to induce weight loss, though not statistically significant. This can be attributable to the fact that this meat sauce can induce appetite but cannot supply adequate body requirements needed for daily activities.

Groups B and C had decreased TG compared to baseline, Groups D and E had increase in TG. There was also a decrease in LDL in Groups C compared to baseline. The Group C rats were fed with 50\% Yaji and a reduction in LDL is a good value for cardiovascular health. This may be due to the constituents found in Yaji, such as garlic which has been reported to lower blood cholesterol $[25,26]$.

This study also shows that Yaji as a complex mixture has the potentials to induce weight loss, though not statistically significant. This can be attributable to the fact that this meat sauce can induce appetite but cannot supply adequate body requirements needed for daily activities.

The weight changes could be due to change in diet.

My study on the biochemical changes in rats after Yaji consumption showed varied degree of changes in the electrolytes (Sodium, Potassium, Bicarbonate and Chloride ions) estimated. The results of this study have also shown that Yaji has the potential to alter the values of Packed Cell Volume (PCV). This response to the ingestion of Yaji in a proportion higher than the normal feed is suggestive of the fact that the constituents of Yaji in combination can induce anemia.

\section{Conclusion}

This study showed that the consumption of Yaji in large amounts could cause liver damage, anaemia, electrolyte derangement and could also affect fat metabolism. There was no effect on the urea and creatinine levels. Yaji, as a meat sauce could be consumed with the normal diet in moderate quantity compared with the daily diet and not to be used as a substitute for food as this could cause a reduction in weight. It follows that the consumption of Yaji in excess could cause injury to some vital cells (such as the liver) with subsequent release of these enzymes into the blood stream. If the consumption of large amount of Yaji should be prolonged, organ damage may likely set in.

\section{Recommendation}

These findings are observed in animals; similar studies could be done in humans to correlate these findings, but before then the consumption of Yaji should be done in moderation and with caution; as the findings in the animals may not be different if extrapolated to humans.

\section{References}

[1] Ezissi Anthony I, Ezejindu Damian N., Ejimo for Obioma C. (2014); A Study on the Histological Effects of Consumption of Yaji on the Liver of Wistar Rats. J Pharm Biomed Sci; 04 (02): 106-112. 
[2] Nwaopara A. O., Odike M. A. C., Inegbenebor U., Adoye M. I. (2007): "The Combined effects of excessive consumption of ginger, clove, red pepper and black pepper on the histology of the liver." Pakistan Journal of Nutrition. 6 (6): 524-527.

[3] Zehra K, Iffat F, Shaghufta P, Saima S M; (2017): Monosodium glutamate: Review on clinical reports; International Journal of Food Properties; vol 20 (2): 1807-1815.

[4] Martin L. J., Sieber F. E., Traystman R. J. (2000): “Apoptosis and necrosis occur in separate neuronal populations in hippocampus and cerebellum after ischemia and are associated with differential alterations in metabotropic glutamate receptor signaling pathways." Journal of Cerebral Blood Flow and Metabolism. 20: 153-167.

[5] Ukoha U., Ogugua E., Adesanmi H., Maduka S., Anyabolu A., Ezejindu D., Umeasalugo K., Ofoego U. (2013): "Effect of Yaji on the Anterior Pituitary Gland. Journal of Biology, Agriculture and Healthcare. 3 (15): 22-24.

[6] Nwaopara A. O., Odike M. A. C., Inegbenebor U., Nwaopara S. O. and Ekhoye E. I. (2008): "A comparative study on the effects of excessive consumption of ginger, clove, red pepper and black pepper on the histology of the heart." Electronic Journal of Biomedicine. 3 (3): 61-64.

[7] Theeraphan C, Issaraporn S, Luchai B, Surapon S; (2018): 6gingerol content of ginger (Zingiberofficinale Roscoe) by different drying methods; Science Direct 10: 24.

[8] Diego FC, Claudia RF, Wanderley PO (2014): Clove (Syzygium aromaticum): a precious spiceAsian Pac $J$ Trop Biomed. 4 (2): 90-96.

[9] Bortolotti M., Coccia G., Grossi G., Miiglioli M. (2011): “The treatment of functional dyspepsia with red pepper." Alimentary Pharmacology and Therapeutics. 16: 1075-82.

[10] McGee H. (2004): "On food and Cooking; the Science and Lore of the Kitchen.” New York, Scribner. pp: 427-429.

[11] Ueki S., Miyoshi M., Shido O., Hasegawa J., Watanabe T. (2008): Systemic administration ofgingerol, a pungent constituent of ginger, induces hypothermia in rats via an inhibitory effect on metabolic rate, European Journal of Pharmacology. 584 (1): 87-92.

[12] Funk, Janet L., Frye, Jennifer B., Oyarzo, Janice N., Timmermann, Barbara N. (2009):"Comparative Effects of Two Gingerol-Containing Zingiberofficinale Extracts on Experimental Rheumatoid Arthritis."JournalOf Natural Products72 (3): 403-407.

[13] Jeong C. H., Bode A. M., Pugliese A., Cho Y. Y., Kim H. G., Shim J. H., Jeon Y. J., Li H. (2009): "Gingerol suppresses colon cancer growth by targeting leukotriene A4 hydrolase." Cancer Research. 69 (2): 5584-5591.
[14] Lee K., Takayuki S., (2008): Antioxidant property of aroma extract isolated from clove buds (Syzygiumaromaticum (L.) Merr.et Perry). Food Chemistry. 74 (4): 443-448.

[15] Rhode J., Fogoros S., Zick S., Wahl H., Griffith K. A., Huang J., Liu J. R. (2007): "Ginger inhibits cell growth and modulates angiogenic factors in ovarian cancer cells." $B M C$ Complement Alternative Medicine. 7: 44.

[16] Thompson, D. C; Barhoumi, R; Burghardt, R. C (1998). "Comparative toxicity of eugenol and its quinonemethidemetabolite in cultured liver cells using kinetic fluorescence bioassays". Toxicology and applied pharmacology149 (1): 55-63. doi: 10.1006/taap.1997.8348. PMID 9512727.

[17] Hartnoll G., Moore D., Douek D. (1993): "Near fatal ingestion of oil of cloves." Archives of Disease in Childhood. 69 (3): 392-393.

[18] Abdel-Salam, Omar M. E. (2014): "Capsaicin as a Therapeutic Molecule” Springer, ISBN 978-3-038-0827-9.

[19] Gooding S. M., Canter P. H., Coelho H. F., Boddy K., Ernst E. (2010): "Systematic review of topical capsaicin in the treatment of pruritus." International Journal of Dermatol. 49 (8): 858-865.

[20] Neelima P., Shashi K. (2008): "Piperine, a major component of black pepper, has cytoprotective and immune modulating properties." Green Medical infomative summary.

[21] Bhattacharjee S. and Sengupta A. (2009): "Spices in cancer prevention: An overview. Internet." Nutrition Wellness 7 (1) 23-26.

[22] Elegbede J. A. (1998): Legumes. "Nutritional Quality of plant Foods."Post harvest Research Unit, Biochemistry Department, University Of Benin, Benin City. Chap 3 Pp. 5383 ed.

[23] Adebisin A. A., Saromi O. T., Amusa N. A., Fagade S. O. (2001): Microbiological quality of some groundnut products hawked in Bauchi, a Nigerian city." Journal of food technology in Africa. 6 (2): 54-59.

[24] Parker R: (2008): "MSG Spice Causes Obesity?" http://www.eurekalert.org/pub_releases/2008-08/uoncurf081308.php

[25] Elkins R., Tenney L. (1996): "Garlic: Nature's amazing nutritional and medicinal wonder food, wood and publishing." Incorporated Pleasant Groove. U T, 84062.

[26] Cardelle-Cobras A., Soria AC., Corza-Martinez M., Villamiel M. (2010): "A comprehensive survey of garlic consumption and health." Pacurar M and Krejci G (Eds). Nova Science Publishers Incorporation. 1-60. 